\title{
Creativity in Teams: The Impact of Team Members' Affective Well-Being and Diversity
}

\section{Ingrid Dackert}

Faculty of Culture and Society, Malmö University, Malmö, Sweden

Email: Ingrid.dackert@mah.se

How to cite this paper: Dackert, I. (2016) Creativity in Teams: The Impact of Team Members' Affective Well-Being and Diversity. Open Journal of Social Sciences, 4, 19-28.

http://dx.doi.org/10.4236/jss.2016.49003

Received: May 16, 2016

Accepted: September 19, 2016

Published: September 22, 2016

\begin{abstract}
The purpose of the research reported in this article was to examine how team members' affective well-being influences creativity in teams. Furthermore, the impact of diversity in gender, age and education on affective well-being and team creativity was investigated. Twenty-nine project teams with 173 team members, involved in projects for 20 weeks as a part of a project management course, participated in the study. In terms of diversity dimensions, age and education were found to have no significant influence either on affective well-being or team creativity. Diversity in gender had a significant positive impact on contentment. Team member enthusiasm was found to have a strong direct impact on team creativity, while contentment had an indirect effect. The results support the integration of affects into creativity theory. In addition, the result suggests managers to focus more on the feelings of the team members and the interaction in the team in order to facilitate well-being and creativity.
\end{abstract}

\section{Keywords}

Team, Well-Being, Creativity, Diversity

\section{Introduction}

The application of teamwork has increased within all types of organizations over the last decades. Indeed, work teams and project teams are frequently used to generate and to implement new ideas [1]-[3]. This may be due to the assumption that a group of people can produce something exceeding that which each of them could produce alone. Amabile and Pillemer [4] highlighted the team context as a key aspect of the external social environment in the componential theory of creativity. The creative synergy in teams is related to the cognitive input as heterogeneous perspectives, team member characteristics and interpersonal interaction that may promote creativity. Diversity among the team members in different aspects can aid the creative process but also 
make it more difficult by limiting common understanding [5].

A dynamic relationship between individual and team-level creativity has been suggested [6]. Cropley and Cropley [7] claimed that individual psychological factors and processes were not adequately addressed in research on organizational creativity. The role of individual processes or outcomes, such as affects and individual creative behaviour, has not been stressed so much in team research [8]. Tagger [9] [10] explored the relationship between individual creativity and group creativity and found that individual creativity as well as team creativity-relevant processes influenced group creativity. In addition, team member creativity, team processes and team creativity have been addressed in other studies suggesting a multi-level framework of team creativity [11] [12]. However, the influence of individual affects on team creativity has not so far been studied.

The aim of the present study was to examine the relationship between team members' affective well-being and team creativity in project teams. Furthermore, the purpose was to examine the impact of diversity in gender, age and educational background on team members' affective well-being and team creativity.

\section{Literature Review}

\subsection{Team Member Affects and Team Creativity}

The influence of mood on creativity has been studied widely, mainly in laboratory settings. In a meta-analysis of research of the relationship between mood and creativity, Bass, De Dreu, and Nijstad [13] concluded that positive mood states, such as happiness, facilitate creativity. Furthermore, a combination of tone and activation has been suggested to capture the affective space. Happy and elated are examples of mood states that are activating and positive in tone. De Dreu, Nijstad, and Bass [14] proposed that individuals with strong behavioural activation are more creative due to increased flexibility.

Result from a field study of the affective-creative relationship at work indicated that positive affect was positively related to creativity, and cognitive variation is suggested as an important mediation process. Positive affect increases cognitive flexibility and the probability that cognitive element will be associated in new ways [15]. Amabile et al. [15] argued that affect need to be integrated into theories of creativity. Affect has also been found to mediate the relationship between cognitive style diversity and perceived creativity in a study conducted by Kurtzberg [16]. Furthermore, organizational creativity and individual psychological well-being has been shown to be related [17].

In the current study, a model of affective well-being developed by Warr [18] [19] was adopted. This model sets its starting-point in the same theoretical models as the abovementioned research on mood, which involves pleasure (tone) and arousal (activation) [20]. Combining pleasure (horizontal axis) with arousal (vertical axis), Warr [18] then added two diagonal axes to the model: depression-enthusiasm and anxiety-contentment. Depression is experienced when arousal and pleasure are both low, while enthusiasm is experienced when they are both high. Anxiety is experienced when pleasure is low and anxiety is high, while contentment is experienced under the opposite condi- 
tions.

Warr [18] found that affective well-being is associated with psychological growth and self-actualization. An advantage of using Warr's model to capture team members' affective well-being is that it is in line with intrinsic motivation described by Amabile [21], and which is confirmed to be related to creativity. Intrinsic task motivation means that a task is undertaken because it is interesting, involving, personally challenging or satisfying [22]. Later, Warr [19] also related his model to the concept of happiness, as affective well-being, happiness can be captured through the combination of enthusiasm and contentment.

\subsection{Diversity, Affective Well-Being and Team Creativity}

The effects of different types of diversity on team creativity and innovation have been addressed in several studies [23]-[26]. The research focuses on demographic diversity as well as heterogeneity in function and education. However, the result of diversity research, in general, is inconsistent [27]. One key issue is how diversity affects team outcome as team creativity as well as group member subjective well-being. Exposure to diverse knowledge and perspectives, due to gender, age or education, may facilitate creativity in teams through increasing the cognitive resources available in the creative process [28]. On the other hand, the social life in the team such as social categorization processes may interact with the cognitive processes [27] [29]. Thus, diversity frequently is associated with negative affective reactions [30]. However, different types of diversity have been suggested to have different impact on individual creativity in teams and team performance. Social category diversity, as gender and age, has been found to be related to lower levels of individual creativity and team performance than informational diversity, as educational background, which seems to have a more positive influence [31] [32].

The interaction between cognitive and social processes creates the context of the team members' subjective well-being. Depending on the team's functioning, the individual team member can be supposed to feel anxious, enthusiastic, content, depressed, and so on [18]. Further, the experienced feelings can be assumed to influence how creative the team will be in the project work.

The present study contributes to the understanding of teamwork in exploring the impact of social category and informational diversity on team members' affective well-being as well as creativity in teams. Furthermore, the influence of individual affects on team creativity is examined. A model of the relationship between diversity in gender, age and education, enthusiasm and contentment, and perceived team creativity was created in order to test the following hypotheses:

H1: Diversity in gender and age has a negative influence on affective well-being and perceived team creativity

H2: Diversity in educational background has a positive influence on affective wellbeing and perceived team creativity

H3: Team members' affective well-being has a positive impact on perceived team 
creativity.

\section{Method}

\subsection{Participants and Setting}

The participants were undergraduate students in a 20-week project management course. Most of the participants had previously studied other subjects and now wanted to strengthen their education with the project management course to make them more attractive on the employment market.

The students' main task during the course was to perform a real project and to analyze the project process and outcome in relation to the course literature. The students organized themselves into project teams at the beginning of the course and were free to choose their project's subject within the frame of creating a new service or product. Commercial, as well as non-profit projects were initiated. The project teams worked autonomously and had no formal leader.

Data were collected from five project management courses. Each team member answered a questionnaire following a lecture midway through the course. At that time, the project teams had been working together for approximately two months. Students that were not present at the lecture had the questionnaire sent to their home address. The questionnaire contained questions about gender, age, earlier education and which project team the participant was a member of. Furthermore, the team members judged their affective well-being in the team's work and their perception of the team's creativity. The completed questionnaires were either handed in or sent in anonymously.

In the present study teams with a response rate of $80 \%$ or higher was included. The number of team members ranged from 4 to 10 and in total 173 team members within 29 teams answered the questionnaire. The gender breakdown was $66 \%$ female and $34 \%$ male. The breakdown of age categories was as follows: under 25 years, $61 \%$, between 25 and 35 years, $31 \%$, 36 years or older, $8 \%$. Regarding educational background, $82 \%$ had studied other subjects at the university before entering the project management course, while $70 \%$ had studied longer than one and a half years. Their earlier studies were coded into two categories, science (for example mathematics and engineering) and arts (for example literature and sociology). Of these, $62 \%$ were classified as students in arts, and $38 \%$ students in science.

\subsection{Measures}

\subsubsection{Diversity Assessment}

Age, gender and educational background were all measured as categorical variables. The formula recommended by Teachman [33] in which data are categorical, was used to compute team diversity for each diversity dimension. Age was re-coded into two categories (under 25 years and 25 years and older), which means that all diversity variables had the same number of categories and were, thus, comparable [34]. The diversity score varied between 0.00 (team members from only one category) and 0.70 (the same proportion of team members from both categories). 


\subsubsection{Well-Being Assessment}

The two scales developed by Warr [18] were used to measure well-being. The depression-enthusiasm scale contains six adjectives: depressed, gloomy, miserable, cheerful, enthusiastic and optimistic. The anxiety-contentment scale also consists of six adjectives: tense, uneasy, worried, calm, contented and relaxed. The respondents indicated on a six-point scale to which degree the work in the project team made them feel like the adjectives. The response scale ranges from never (1) to all of the time (6). The first three items in each scale is reverse coded so that the summary scores indicate enthusiasm and contentment. Cronbach's alpha was 0.85 for the depression-enthusiasm scale and 0.73 for the anxiety-contentment scale in the current study.

\subsubsection{Team Creativity Assessment}

In order to measure team creativity, the team member's subjective ratings were used. This is in line with Runco's [35] argument that from a process-oriented view, creativity may better be captured through participant subjective ratings than expert ratings. The perceived degree of team creativity was measured with two items in line with Amabile, Burnside and Gryskiewicz [36]. The respondents judged on a scale with seven steps how creative respectively innovative their team was. Cronbach's alpha was 0.85 .

\subsection{Data Analysis}

The data analyses were conducted at an individual level. The reason for this is that well-being is essentially an individual-level concept, which loses meaning if aggregated to a team level [37]. SPSS 20 was used for the data analyses. Means and standard deviation for the scales was calculated. Correlation analysis was conducted applying Pearson's product moment correlation (Table 1).

In order to test the impact of diversity on well-being and team creativity as well as the impact of enthusiasm and contentment on perceived team creativity, a LISREL 8.72 structural equation modeling was carried out [38]. The first path diagram testing the relationships between diversity in gender, age and education and enthusiasm, contentment and team creativity showed a poor fit between the predicted and the observed

Table 1. Means, standard deviations, and correlations between diversity variables, and enthusiasm, contentment and team creativity $(\mathrm{N}=173)$.

\begin{tabular}{cccccc}
\hline & Mean & SD & Enthusiasm & Contentment & Team Creativity \\
\hline Gender Diversity & 0.44 & 0.29 & -0.06 & 0.09 & -0.06 \\
Age Diversity & 0.55 & 0.19 & -0.07 & -0.06 & -0.02 \\
Educational Diversity & 0.49 & 0.29 & 0.03 & 0.04 & -0.02 \\
Enthusiasm & 4.93 & 0.77 & & $0.78^{* *}$ & $0.47^{* *}$ \\
Contentment & 4.61 & 0.79 & & & $0.36^{* *}$ \\
Team Creativity & 4.95 & 1.24 & & & \\
\hline
\end{tabular}

${ }^{* *} \mathrm{p}<0.01$. 
covariance matrices $\left(X^{2}=97.08, \mathrm{df}=7, p=0.00, \mathrm{RMSEA}=0.754\right)$. The modification index suggested a path between enthusiasm and contentment. After adding that relationship the model (Figure 1$)$ fitted the data perfectly $\left(X^{2}=0.00, \mathrm{df}=0, p=1.00\right.$, RMSEA $=0.00)$.

\section{Results}

Descriptive statistics and correlation are presented in Table 1. The results show that among the diversity variables, age had the highest diversity within the teams, followed by educational background and gender. Furthermore, it can be seen that the two wellbeing variables were rated rather highly by the team members, indicating that the work in the project teams made them feel enthusiastic most of the time and made them feel content often to most of the time. The team members perceived the team creativity as relatively high.

As can be seen in Table 1, the correlation analysis showed no significant correlations between the diversity variables and the well-being variables or perceived team creativity. The result also showed that the correlation between the two well-being variables was high and significant $(r=0.78, p<0.01)$. In addition, the result showed that perceived team creativity was positively and significantly correlated with enthusiasm $(\mathrm{r}=0.47, \mathrm{p}$ $<0.01)$ and contentment $(\mathrm{r}=0.36, \mathrm{p}<0.01)$.

The result of the structural equation modeling is presented in Figure 1. The estimates between gender and age diversity and enthusiasm were negative. The result showed a positive estimate between educational diversity and enthusiasm. However, none of these estimates were significant. The estimates between age and educational diversity and contentment were low and non-significant. The estimate between gender diversity and contentment was positive and significant $(\mathrm{t}(173)=2.72, \mathrm{p}<0.05)$.

Further, the result showed that the estimates between diversity in gender and educational background and team creativity were low and negative. The estimate between age diversity and team creativity was positive. None of these estimates were significant.

The estimate between the two well-being dimensions was positive and significant

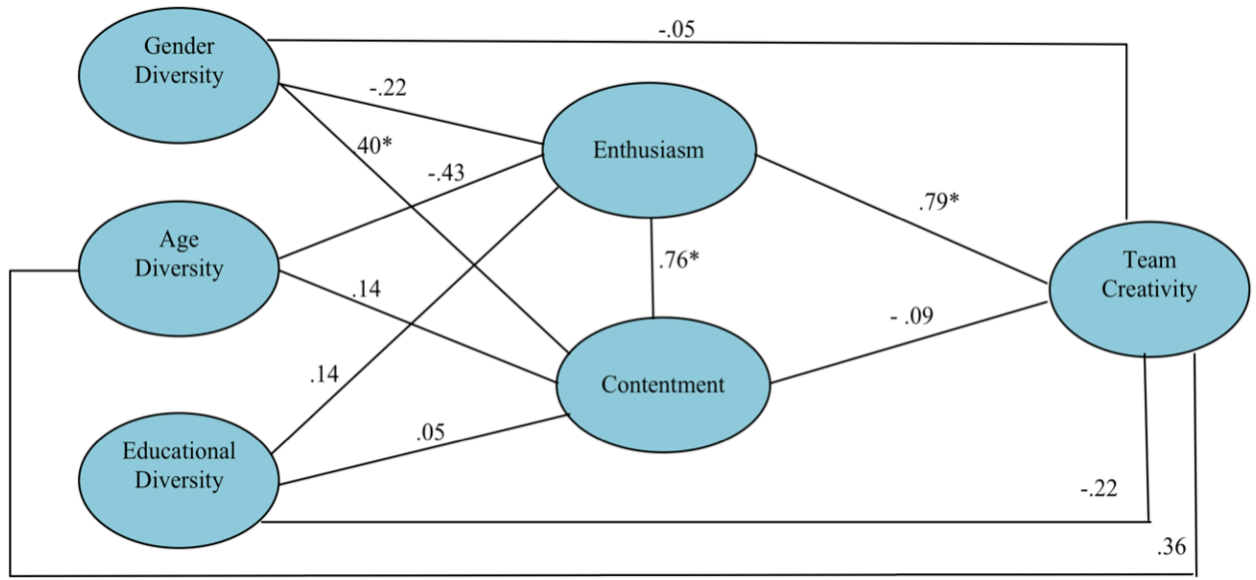

Figure 1. Path diagram presenting the estimates between the variables ${ }^{*} \mathrm{p}<0.05$. 
$(t(173)=14.80, p<0.05)$. Moreover, the estimate between enthusiasm and team creativity was positive and significant $(\mathrm{t}(173)=4.71, \mathrm{p}<0.05)$. The result also showed that the estimate between contentment and perceived team creativity was low and non-significant.

\section{Discussion}

The purpose of the present study was to examine how gender, age and educational diversity influenced the team members' affective well-being and perceived team creativity, and to investigate the impact of the team members' affective wellbeing on perceived team creativity.

Regarding the influence of gender and age diversity on well-being and team creativity the result indicates that gender diversity has a significant positive impact on contentment. No other significant relationships were found, which meant that the first hypothesis was not confirmed. The second hypothesis proposed a positive influence of diversity in educational background on well-being and team creativity. However, the result showed almost there was no relationship to the well-being dimensions and a negative but not significant relationship to team creativity. This result can be interpreted in light of the double influence of differences in knowledge and perspectives [5] [21]. A heterogeneous set of perspectives may have a positive influence on creativity. However, differences may also hinder a shared understanding of the goal and how to handle the task in the team. To develop shared understanding in diverse teams can be supposed to take longer time than in more homogeneous teams. The teams in the current study had worked together for about two months, which may not have been enough time to develop a common view.

Concerning the impact of affective well-being on team creativity, the result showed that team member enthusiasm had a strong impact on team creativity as proposed in the third hypothesis. However, the result pointed to that the dimension anxiety-contentment was not related to creativity within the project teams. A strong and significant positive relationship between contentment and enthusiasm was found indicating an indirect influence of the anxiety-contentment dimension on team creativity.

The present study was carried out in the context of autonomous project teams and the team members were students taking part in a project management course. Conducting research with students as participant is relevant when the setting is similar to a real organizational context [11]. Most of the participants in this study had finished their education and could thus be comparable to employees in teams in organizations. The teams worked autonomously as many teams in organizations did and the result showed that the team members experienced high levels of enthusiasm and contentment, and they perceived their teams to be highly creative. This result is in agreement with the intrinsic motivation principle of creativity postulated by Amabile [21]. A work environment with high autonomy may encourage creativity as it provides space for the team members to be motivated by their interest in and the challenge of the work itself [22].

The cross-sectional design of this study is a limitation. The interaction between indi- 
vidual affective well-being and team creativity was only captured on one occasion during the project process. To follow the teams over time, adopting a longitudinal design, would have gained deeper knowledge of the interplay between the team members' affects and team creativity. Another limitation may be that affective well-being and team creativity were self-rated by the team members which may bring a risk of common method bias. However, Kurtzberg [5] argues that creativity within a project team may be the result of a complicated interaction involving the team's dynamics, the work process and the resulting products. Thus, it would be appropriate to rely on team members' subjective judgments of team creativity, even if no objective judgments are present. When answered the questionnaire the teams were halfway in their project work and not so many outcomes in the sense of concrete products or services were present to judge so far.

The present study contributes to the understanding of how team member's feelings and affective well-being influence creativity in teams. The result supports Amabile's and Mueller's [22] development of part of the componential theory of creativity to integrate affect. The result of the current study also suggests a model of affects that may be valuable for further research on creativity in teams [18].

Furthermore, the study has implications for managing creativity in teams. The best way to encourage creativity in teams seems to be to focus on the team members and their interaction, rather than the team composition. How the team members feel about the teamwork indicates how the creative process in the team proceeds. If diverse teams are created in order to include different perspectives and knowledge it seems to be of special importance to help the team to manage both cognitive and social processes to facilitate well-being and creativity.

\section{References}

[1] Hülsheger, U.R., Anderson, N. and Salgado, J.F. (2009) Team-Level Predictors of Innovation at Work: A Comprehensive Meta-Analysis Spanning Three Decades of Research. Journal of Applied Psychology, 94, 1128-1145. http://dx.doi.org/10.1037/a0015978

[2] Rasmussen, T.H. and Jeppesen, H.J. (2006) Teamwork and Associated Psychological Factors: A Review. Work \& Stress, 20, 105-128. http://dx.doi.org/10.1080/02678370600920262

[3] Sundström, P. and Zika-Viktorsson, A. (2009) Organizing for Innovation in a Product Development Project. Combining Innovative and Result Oriented Ways of Working-A Case Study. International Journal of Project Management, 27, 745-753. http://dx.doi.org/10.1016/j.ijproman.2009.02.007

[4] Amabile, T.M. and Pillemer, J. (2012) Perspectives on the Social Psychology of Creativity. Journal of Creative Behavior, 46, 3-15. http://dx.doi.org/10.1002/jocb.001

[5] Kurtzberg, T.R. and Amabile, T.M. (2001) From Guilford to Creative Synergy: Opening the Black Box of Team-Level Creativity. Creativity Research Journal, 13, 285-294. http://dx.doi.org/10.1207/S15326934CRJ1334_06

[6] Moneta, G.B., Amabile, T.M., Schatzel, E.A. and Kramer, S.J. (2010) Mulitrater Assessment of Creative Contribution Team Projects in Organizations. European Journal of Work and Organizational Psychology, 19, 150-176. http://dx.doi.org/10.1207/S15326934CRJ1334_06

[7] Cropley, D. and Cropley, A. (2012) A Psychological Taxonomy of Organizational Innova- 
tion: Resolving the Paradoxes. Creativity Research Journal, 24, 29-40. http://dx.doi.org/10.1080/10400419.2012.649234

[8] Mathieu, J., Maynard, M.T., Rapp, T. and Gilson, L. (2008) Team Effectiveness 1997-2007: A Review of Recent Advancements and a Glimpse into the Future. Journal of Management, 34, 410-476. http://dx.doi.org/10.1177/0149206308316061

[9] Taggar, S. (2001) Group Composition, Creative Synergy, and Group Performance. Journal of Creative Behavior, 35, 261-286. http://dx.doi.org/10.1002/j.2162-6057.2001.tb01050.x

[10] Taggar, S. (2002) Individual Creativity and Group Ability to Utilize Individual Creative Resources: A Multiple Model. Academy of Management Journal, 45, 315-330. http://dx.doi.org/10.2307/3069349

[11] Bissola, R. and Imperatori, B. (2011) Organizing Individual and Collective Creativity: Flying in the Face of Creativity Clichés. Creativity and Innovation Management, 20, 77-89. http://dx.doi.org/10.1111/j.1467-8691.2011.00597.x

[12] Pirola-Merlo, A. and Mann, L. (2004) The Relationship between Individual Creativity and Team Creativity: Aggregating across People. Journal of Organizational Behavior, 25, 235-257. http://dx.doi.org/10.1002/job.240

[13] Bass, M., De Dreu, C.K.W. and Nijstad, B.A. (2008) A Meta-Analysis of 25 Years of Mood-Creativity Research: Hedonic Tone, Activation, or Regulatory Focus? Psychological Bulletin, 134, 779-806. http://dx.doi.org/10.1037/a0012815

[14] De Dreu, C.K.W., Nijstad, B.A. and Bass, M. (2011) Behavioral Activation Links to Creativity Because of Increased Cognitive Flexibility. Social Psychological and Personality Science, 2, 72-80. http://dx.doi.org/10.1177/1948550610381789

[15] Amabile, T.M., Barsade, S.G., Mueller, J.S. and Staw, B.M. (2005) Affect and Creativity at Work. Administrative Science Quarterly, 50, 367-403. http://dx.doi.org/10.2189/asqu.2005.50.3.367

[16] Kurtzberg, T.R. (2005) Feeling Creative, Being Creative: An Empirical Study of Diversity and Creativity in Teams. Creativity Research Journal, 17, 51-65. http://dx.doi.org/10.1207/s15326934crj1701_5

[17] Rasulzada, F. and Dackert, I. (2009) Organizational Creativity and Innovation in Relation to Psychological Well-Being and Organizational Factors. Creativity Research Journal, 21, 191-198. http://dx.doi.org/10.1080/10400410902855283

[18] Warr, P. (1990) The Measurement of Well-Being and Other Aspects of Mental Health. Journal of Occupational and Organizational Psychology, 63, 193-210. http://dx.doi.org/10.1111/j.2044-8325.1990.tb00521.x

[19] Warr, P. (2007) Work, Happiness and Unhappiness. Lawrence Erlbaum Associates Publisher, London.

[20] Watson, D. and Tellegen, A. (1985) Towards a Consensual Structure of Mood. Psychological Bulletin, 98, 219-235. http://dx.doi.org/10.1037/0033-2909.98.2.219

[21] Amabile, T.M. (1996) Creativity in Context. Update to the Social Psychology of Creativity. Westview, Boulder.

[22] Amabile, T.M. and Mueller, J.S. (2008) Studying Creativity, Its Processes, and Its Antecedents: An Exploration of the Componential Theory of Creativity. In Zhou, J. and Shalley, C.E., Eds., Handbook of Organizational Creativity, Lawrence Erlbaum Associates, New York, 33-64.

[23] Cady, S.H. and Valentine, J. (1999) Team Innovation and Perceptions of Consideration. What Differences Does Diversity Make? Small Group Research, 30, 730-750. 
http://dx.doi.org/10.1177/104649649903000604

[24] Curseu, P.L. (2010) Team Creativity in Web Site Design: An Empirical Test of a Systemic Model. Creativity Research Journal, 22, 98-107. http://dx.doi.org/10.1080/10400410903579635

[25] Hütterman, H. and Boerner, S. (2011) Fostering Innovation in Functionally Diverse Teams: The Two Faces of Transformational Leadership. European Journal of Work and Organizational Psychology, 20, 833-854. http://dx.doi.org/10.1080/1359432X.2010.524412

[26] Shin, S.J. and Zhou, J. (2007) When Is Educational Specialization Heterogeneity Related to Creativity in Research and Development Teams? Transformational Leadership as a Moderator. Journal of Applied Psychology, 92, 1709-1721. http://dx.doi.org/10.1037/0021-9010.92.6.1709

[27] van Knippenberg, D. and Schippers, M.C. (2007) Work Group Diversity. Annual Review of Psychology, 58, 515-541. http://dx.doi.org/10.1146/annurev.psych.58.110405.085546

[28] Nijstad, B.A. and Paulus, P.B. (2003) Group Creativity: Common Themes and Future Directions. In: Nijstad, B.A. and Paulus, P.B., Eds., Group Creativity: Innovation through Collaboration, Oxford University Press, New York. http://dx.doi.org/10.1093/acprof:oso/9780195147308.003.0015

[29] Paulus, P.B. and Dzindolet, M. (2008) Social Influence, Creativity and Innovation. Social Influence, 3, 228-247. http://dx.doi.org/10.1080/15534510802341082

[30] Mannix, E. and Neale, M.A. (2005) What Differences Make a Difference: The Promise and Reality of Diverse Teams in Organizations. Psychological Science in the Public Interest, 6, 31-55. http://dx.doi.org/10.1111/j.1529-1006.2005.00022.x

[31] Jehn, K.A., Northcraft, G.B. and Neale, M.A. (1999) Why Differences Make a Difference: A Study of Diversity, Conflicts, and Performance at Work. Administrative Science Quarterly, 44, 741-763. http://dx.doi.org/10.2307/2667054

[32] Thatcher, S.M.B. and Brown, S.A. (2010) Individual Creativity in Teams: The Importance of Communication Media Mix. Decision Support Systems, 49, 290-300. http://dx.doi.org/10.1016/j.dss.2010.03.004

[33] Teachman, J.D. (1980) Analysis of Population Diversity. Measures of Qualitative Variation. Sociological Methods \& Research, 8, 341-362. http://dx.doi.org/10.1177/004912418000800305

[34] Harrison, D.A. and Klein, K.J. (2007) What's the Differences? Diversity Constructs as Separation, Variety, or Disparity in Organizations. Academy of Management Review, 32, 1199-1228. http://dx.doi.org/10.5465/AMR.2007.26586096

[35] Runco, M.A. (2005) Motivation, Competence, and Creativity. In: Elliot, A. and Dweck, C., Eds., Handbook of Motivation and Competence, Guilford Press, New York.

[36] Amabile, T.M., Burnside, R. and Gryskiewicz, S.S. (1995) User's Guide for KEYS: Assessing the Climate for Creativity. Centre for Creative Leadership, Greensboro.

[37] van Mierlo, H., Rutte, C.G., Kompier, M.A.J. and Doorewaard, H.A.C.M. (2005) SelfManaging Teamwork and Psychological Well-Being. Group and Organization Management, 30, 211-235. http://dx.doi.org/10.1177/1059601103257989

[38] Jöreskog, K.G., Sörbom, D. and DuToit, S.H.C. (2000) LISREL 8: New Statistical Features. Scientific Software International, Lincolnwood. 
Submit or recommend next manuscript to SCIRP and we will provide best service for you:

Accepting pre-submission inquiries through Email, Facebook, LinkedIn, Twitter, etc. A wide selection of journals (inclusive of 9 subjects, more than 200 journals)

Providing 24-hour high-quality service

User-friendly online submission system

Fair and swift peer-review system

Efficient typesetting and proofreading procedure

Display of the result of downloads and visits, as well as the number of cited articles

Maximum dissemination of your research work

Submit your manuscript at: http://papersubmission.scirp.org/ 